\title{
Scavenging Free Radicals To Preserve Enhancement and Extend Relaxation Times in NMR using Dynamic Nuclear Polarization**
}

\author{
Pascal Miéville, Puneet Ahuja, Riddhiman Sarkar, Sami Jannin, * Paul R. Vasos, Sandrine Gerber- \\ Lemaire, Mor Mishkovsky, Arnaud Comment, Rolf Gruetter, Olivier Ouari, Paul Tordo, and \\ Geoffrey Bodenhausen
}

\begin{abstract}
Dynamic nuclear polarization (DNP) can enhance the nuclear polarization, that is the difference between the populations of the Zeeman levels $|\alpha\rangle$ and $|\beta\rangle$ of spin $I=$ $1 / 2$, by up to four orders of magnitude with respect to their Boltzmann distribution at room temperature. ${ }^{[1]}$ This enhancement arises from thermal mixing, which is brought about by microwave saturation of the EPR transitions of stable radicals that are mixed with the sample under investigation before freezing. In dissolution DNP, the sample is usually polarized at low temperatures and moderate magnetic fields $(T=1.2 \mathrm{~K}$ and $B_{0}=3.35$ or $5 \mathrm{~T}$ in our laboratory), ${ }^{[2]}$ rapidly dissolved, ${ }^{[3]}$ and heated to ambient temperature by a burst of water vapor. To minimize losses of nuclear spin polarization, the transfer from the polarizer to the NMR spectrometer or MRI magnet, including the settling of mechanical vibrations and convection currents, and, if required, the infusion into living organisms, must be completed within an interval $T<T_{1}$. In our laboratory, the interval $T$ has recently been lowered to $4.5 \mathrm{~s}$. The
\end{abstract}

[*] P. Miéville, P. Ahuja, Dr. R. Sarkar, Dr. S. Jannin, Dr. P. R. Vasos, Dr. S. Gerber-Lemaire, Prof. G. Bodenhausen Institut des Sciences et Ingénierie Chimiques

Ecole Polytechnique Fédérale de Lausanne

EPFL, Batochime, 1015 Lausanne (Switzerland)

Fax: (+41) 21-693-94 35

E-mail: sami.jannin@epfl.ch

Homepage: http://Irmb.epfl.ch

Dr. M. Mishkovsky, Dr. A. Comment, Prof. R. Gruetter

Laboratory for Functional and Metabolic Imaging

EPFL, 1015 Lausanne (Switzerland)

Dr. O. Ouari, Prof. P. Tordo

Laboratoire LCP, Université d'Aix-Marseille I, II, III et CNRS

Avenue Escadrille Normandie-Niemen

13397 Marseille Cedex 20 (France)

Prof. G. Bodenhausen

Département de Chimie, associé au CNRS

Ecole Normale Supérieure

24 rue Lhomond 75231, Paris Cedex 5 (France)

[**] We thank Prof. Jacques van der Klink of the EPFL, and Dr. Ben van den Brandt, Dr. Jacobus Konter, and Dr. Patrick Hautle of the Paul Scherrer Institute for the design and construction of the DNP polarizer. We gratefully acknowledge Martial Rey for technical assistance. This work was supported by the Swiss National Science Foundation (grant 200020_124694 to G.B. and P.R.V. and grant 200020_124901 to A.C.), the Commission pour la Technologie et I'Innovation (CTI), the Ecole Polytechnique Fédérale de Lausanne (EPFL), and the French CNRS.

()

Supporting information for this article is available on the WWW under http://dx.doi.org/10.1002/anie.201000934. radicals in the hyperpolarized solution lead to an increase of the longitudinal relaxation rate $R_{1}=1 / T_{1}$ of the solute, thus limiting the timescales of the dynamic processes that can be monitored with hyperpolarized nuclei. A concomitant enhancement of the transverse relaxation rates $R_{2}=1 / T_{2}$ leads to undesirable line-broadening. The relaxation rates $R_{\mathrm{LLS}}=$ $1 / T_{\mathrm{LLS}}$ of the populations of long-lived states (LLS) ${ }^{[4]}$ and the decay rates $R_{\mathrm{LLC}}=1 / T_{\mathrm{LLC}}$ of long-lived coherences (LLC) ${ }^{[5]}$ are even more sensitive to the presence of free radicals than populations of eigenstates and single-quantum coherences. Free radicals can be toxic, and hyperpolarized solutions should not be infused into living organisms unless the radicals are removed.

Herein, we demonstrate how $\mathrm{N}$-oxide radicals that are widely used for DNP, such as 4-hydroxy-2,2,6,6-tetramethylpiperidine-1-oxyl (TEMPOL), can be reduced by scavengers like sodium ascorbate (vitamin $\mathrm{C}$ ) during the dissolution process into 2,2,6,6-tetramethylpiperidine-1,4-diol (TEMPOL-H; Scheme 1), thus extending transverse and longitudinal relaxation times of solutes and slowing down the decay of their polarization during and after transfer. Scavenging free radicals with ascorbate merely leaves ascorbyl radicals, which rapidly disproportionate,${ }^{[6]}$ in contrast to scavenging with thiol-based (DTT) or phenolic (Vitamin E) antioxidants, so that no paramagnetic species are present in the sample after dissolution and reduction.<smiles>COC1=C(O)C(=O)O[C@H]1[C@H](O)CO</smiles>
ascorbate<smiles>CC1(C)CC(O)CC(C)(C)N1[O-]</smiles>

TEMPOL

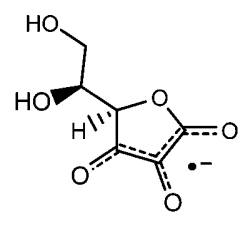

ascorbyl radical
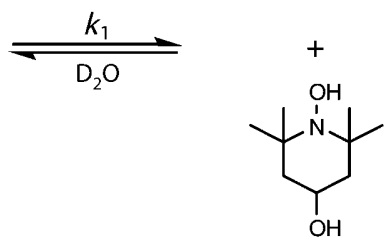

2,2,6,6-tetramethylpiperidine-1,4-diol
Scheme 1. The reduction of TEMPOL by sodium ascorbate, leading to the formation of a delocalized sodium ascorbyl radical and diamagnetic TEMPOL-H. 
We have chosen to illustrate applications of DNP to protons, because proton $T_{1}$ values are most sensitive to the presence of radicals, but dissolution DNP with TEMPOL is equally applicable to ${ }^{13} \mathrm{C}$ (sodium acetate, glycine, ${ }^{[7]}$ alanineglycine ${ }^{[8]}$ ), ${ }^{15} \mathrm{~N}$ (acetylcholine and choline chloride ${ }^{[9]}$ ), ${ }^{129} \mathrm{Xe}$, ${ }^{89} \mathrm{Y}$ (yttrium chloride and complexes ${ }^{[10]}$ ), and ${ }^{6} \mathrm{Li}$ (lithium chloride $\left.{ }^{[11]}\right)$. The frozen beads prepared for DNP contain $30 \mathrm{~mm}$ TEMPOL along with the solute under investigation and glass-forming solvents, such as glycerol/water mixtures. These beads are inserted in the polarizer together with an equal number of beads containing $3 \mathrm{M}$ sodium ascorbate in $\mathrm{D}_{2} \mathrm{O}$. During the dissolution process, all beads melt rapidly and the two solutions become intimately mixed, so that the TEMPOL radicals are reduced by the 100 -fold excess of sodium ascorbate during their voyage from the polarizing magnet to the NMR spectrometer or MRI magnet (see Supporting Information for details).

The kinetics of this reduction process can be studied at room temperature (Figure 1 ) by NMR or ESR. ${ }^{[12]} \mathrm{We}$ observed the growth of the proton signal due to the four
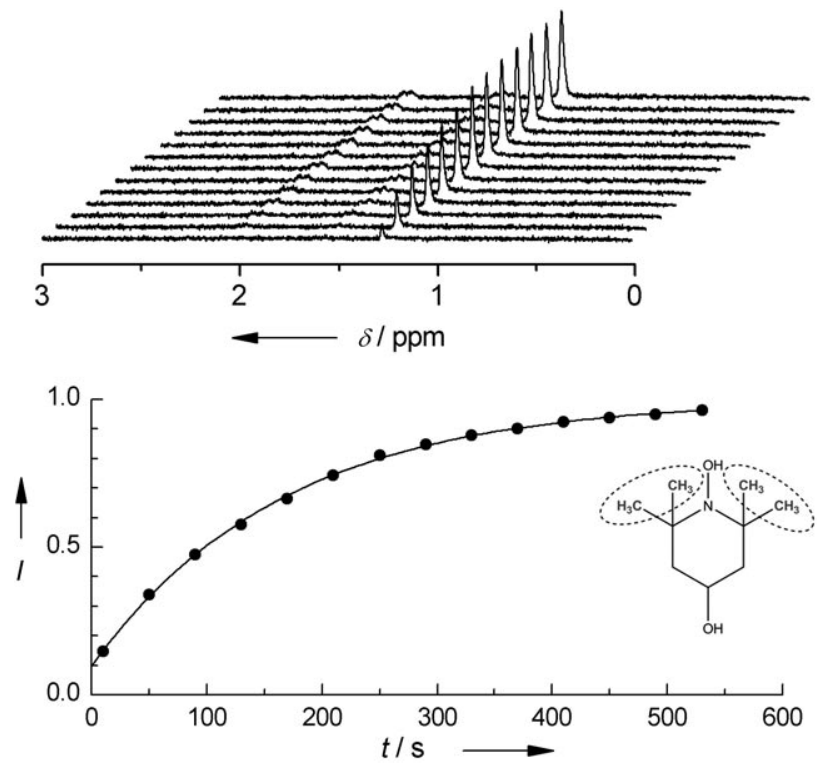

Figure 1. Slow reaction of $2.5 \mathrm{~mm}$ TEMPOL with $30 \mathrm{~mm}$ sodium ascorbate in $\mathrm{D}_{2} \mathrm{O}$ (much less than in the actual DNP experiments) at $T=296 \mathrm{~K}$ in a magnetic field $B_{0}=7.05 \mathrm{~T}(300 \mathrm{MHz}$ for protons). The singlet at $\delta=1.28 \mathrm{ppm}$ that arises from the four degenerate methyl groups in diamagnetic TEMPOL-H $(\bullet)$ appears only after reduction of the paramagnetic TEMPOL.

degenerate methyl groups of TEMPOL-H arising from the reduction of TEMPOL by ascorbate. A second-order rate constant $k_{2}=0.201 \pm 0.005 \mathrm{~L} \mathrm{~mol}^{-1} \mathrm{~s}^{-1}$ was determined with $2.5 \mathrm{~mm}$ TEMPOL and $30 \mathrm{~mm}$ sodium ascorbate. This reduction can be described by a pseudo first-order rate constant $k_{1}=0.0060 \pm 0.0002 \mathrm{~s}^{-1}$. The rate will be much faster with a 100 -fold excess of sodium ascorbate at a higher temperatures.

The scavenging of TEMPOL by ascorbate gives rise to ascorbyl radicals, which have been studied in solvents such as acetonitrile. ${ }^{[13]}$ In the presence of a proton-donating solvent, as in the water/glycerol or water/ethanol mixtures typically used in dissolution DNP, ascorbyl radicals quickly disproportionate $\left(k_{2} \approx 3 \times 10^{5} \mathrm{Lmol}^{-1} \mathrm{~s}^{-1}\right)^{[6]}$ (Scheme 2), resulting in solutions that do not contain any paramagnetic species. Apart from the interest of the method for in-vitro NMR

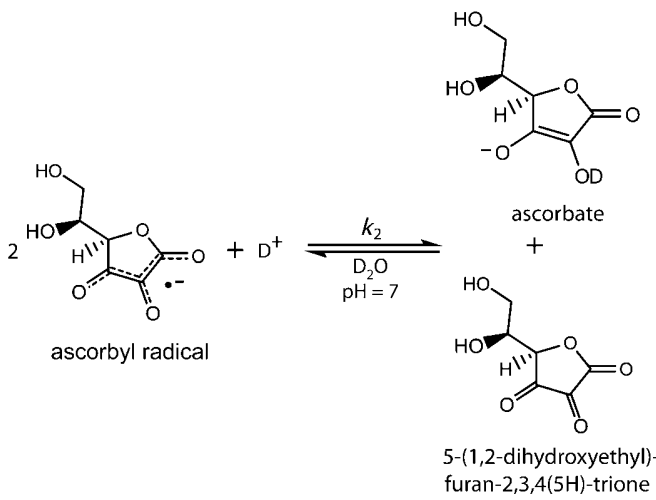

Scheme 2. Disproportionation of ascorbyl radicals into ascorbate and diamagnetic 5-(1,2-dihydroxyethyl)furan-2,3,4(5H)-trione.

spectroscopy, our technique could also be useful for in-vivo studies with hyperpolarized solutions. However, even though ascorbyl radicals disproportionate to compounds that are naturally produced in-vivo after administration of vitamin C, ${ }^{[14]}$ TEMPOL is reduced to 2,2,6,6-tetramethylpiperidine-1,4-diol; the toxicity of the latter compound has not been studied to our knowledge.

Figure 2 shows how the scavenging of TEMPOL by sodium ascorbate leads to a nearly threefold extension of the longitudinal relaxation time of the most isolated proton in acrylic acid $\left(\mathrm{CH}_{2}=\mathrm{CH}^{\mathrm{R}} \mathrm{COOH}\right), \mathrm{H}^{\mathrm{R}}$, which has the longest lifetime $T_{1}$, and to an extension of the $T_{1}$ values of the two diastereotopic $\mathrm{H}^{\alpha}$ glycine protons in L-Ala-Gly by a factor of 1.5. A longer $T_{1}$ value translates into a higher polarization after transfer, by a factor of four in the present example. The reduction of TEMPOL by ascorbate leads to an extension of $T_{1}\left({ }^{13} \mathrm{C}\right)$ in $1{ }^{13} \mathrm{C}$ labeled acetate from $40.1 \pm 0.6 \mathrm{~s}$ to $72 \pm 0.7 \mathrm{~s}$ (a factor of 1.8.)

Transverse relaxation times are also greatly extended by the addition of a scavenger. Figure 3 shows that the $T_{2}$ value of proton $\mathrm{H}^{\mathrm{R}}$ in acrylic acid $\left(\mathrm{CH}_{2}=\mathrm{CH}^{\mathrm{R}} \mathrm{COOH}\right)$ is prolonged by a factor of 3.5, and the $T_{2}$ value of the two diastereotopic $\mathrm{H}^{\alpha}$ glycine protons in L-Ala-Gly by a factor of 1.6.

The lifetimes $T_{\mathrm{LLS}}$ of long-lived states $^{[4]}$ (LLS) are exquisitely sensitive to paramagnetic relaxation. The scavenging of TEMPOL by sodium ascorbate leads to a significant extension (Figure $4 \mathrm{a}$ ) of the lifetimes of the LLS involving the two nearby protons $\mathrm{I}$ and $\mathrm{S}$ in acrylic acid $\left(\mathrm{CH}^{\mathrm{I}} \mathrm{H}^{\mathrm{S}}=\right.$ $\mathrm{CHCOOH}$ ). Likewise, the LLS associated with the two diastereotopic $\mathrm{H}^{\alpha}$ protons in glycine in the dipeptide L-AlaGly has a lifetime that is dramatically extended by a factor of seven by scavenging TEMPOL with ascorbate (Figure $4 \mathrm{~b}$ ). The LLS were excited as described elsewhere ${ }^{[4 \mathrm{~d}]}$ and sustained by CW irradiation at $T=296 \mathrm{~K}$ and $B_{0}=7.05 \mathrm{~T}$, without DNP.

Long-lived coherences ${ }^{[5]}$ (LLCs) are also very sensitive to paramagnetic effects. The scavenging of TEMPOL by sodium 

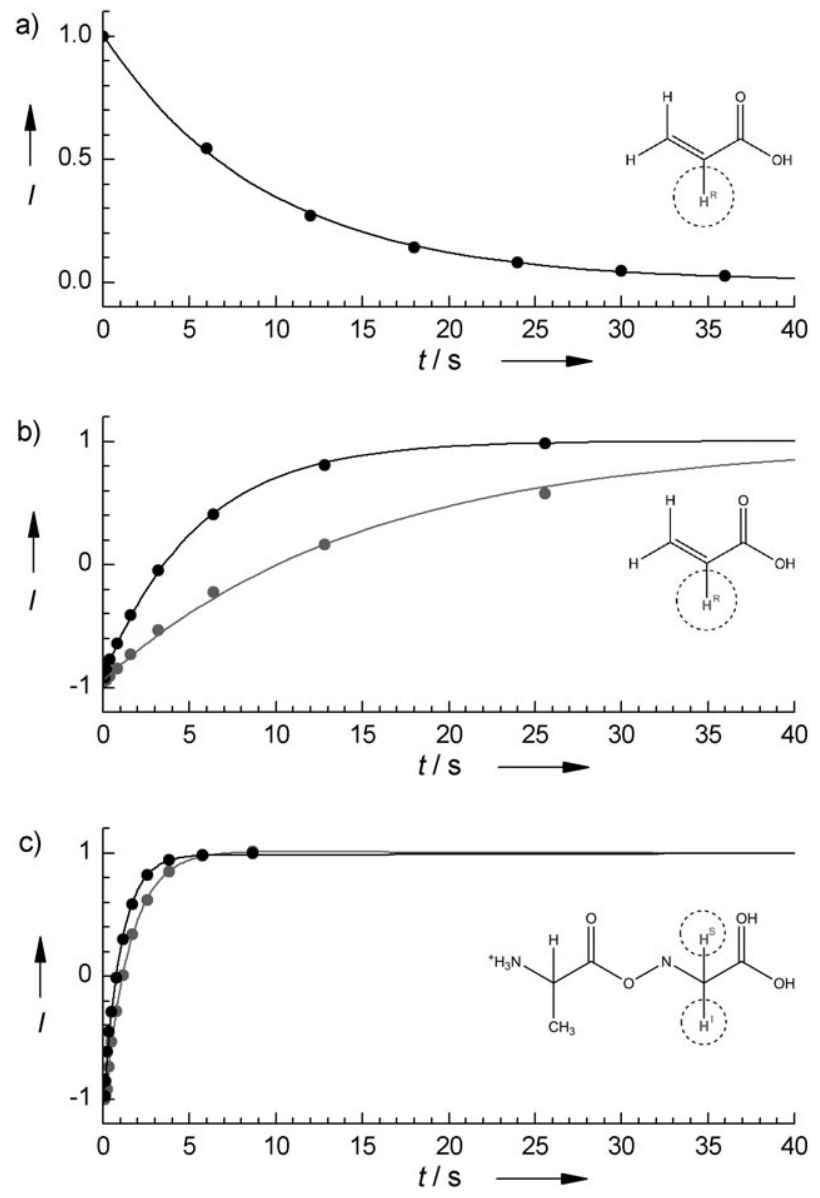

Figure 2. a) Decay of the hyperpolarized magnetization of proton $\mathrm{H}^{\mathrm{R}}$ $\left(T_{1}=9.36 \pm 0.12 \mathrm{~s}\right)$ in acrylic acid $\left(\mathrm{CH}_{2}=\mathrm{CH}^{\mathrm{R}} \mathrm{COOH}\right)$, measured $4.5 \mathrm{~s}$ after dissolution with hot $\mathrm{D}_{2} \mathrm{O}$ of a mixture of frozen beads of acrylic acid containing TEMPOL and frozen beads of $3 \mathrm{M}$ sodium ascorbate (vitamin C). b) Inversion recovery without DNP of proton $\mathrm{H}^{\mathrm{R}}$ in acrylic acid in $\mathrm{D}_{2} \mathrm{O}$ with $2.5 \mathrm{~mm}$ TEMPOL without scavenger $(\bullet$,

$\left.T_{1}=5.35 \pm 0.1 \mathrm{~s}\right)$ and, again without DNP, after addition of $30 \mathrm{~mm}$ sodium ascorbate $\left(\bullet, T_{1}=14.9 \pm 0.8 \mathrm{~s}\right)$. c) Inversion recovery without DNP of the two diastereotopic protons $\mathrm{H}^{\prime}$ and $\mathrm{H}^{\mathrm{S}}$ of glycine in L-AlaGly in $\mathrm{D}_{2} \mathrm{O}$ with $2.5 \mathrm{~mm}$ TEMPOL without scavenger (•

$\left.T_{1}=1.01 \pm 0.05 \mathrm{~s}\right)$ and after addition of $30 \mathrm{~mm}$ sodium ascorbate (e, $\left.T_{1}=1.47 \pm 0.05 \mathrm{~s}\right)$.

ascorbate leads to the extension of the lifetime $T_{\mathrm{LLC}}$ of the LLC involving the two diastereotopic $\mathrm{H}^{\alpha}$ glycine protons in LAla-Gly from $T_{\mathrm{LLC}}=1.43$ to $3.82 \mathrm{~s}$ (Figure 5). This corresponds to a decrease in the linewidth from 226 to $83 \mathrm{mHz}$. The LLCs were sustained by CW irradiation.

In summary, it is possible to quench paramagnetic relaxation arising from the stable radicals that are required for dissolution DNP by adding frozen beads containing a reducing agent such as sodium ascorbate (vitamin C) to the frozen beads containing the substance under investigation combined with stable radicals required for DNP. Other radicals, such as those based on trityl derivatives, may require other specific scavengers $^{[15]}$ as an alternative to mechanical filtering. ${ }^{[16]}$ The use of hyperpolarized spin states with extended lifetimes should allow slower dynamic processes to be studied (such as diffusion or protein folding) with high
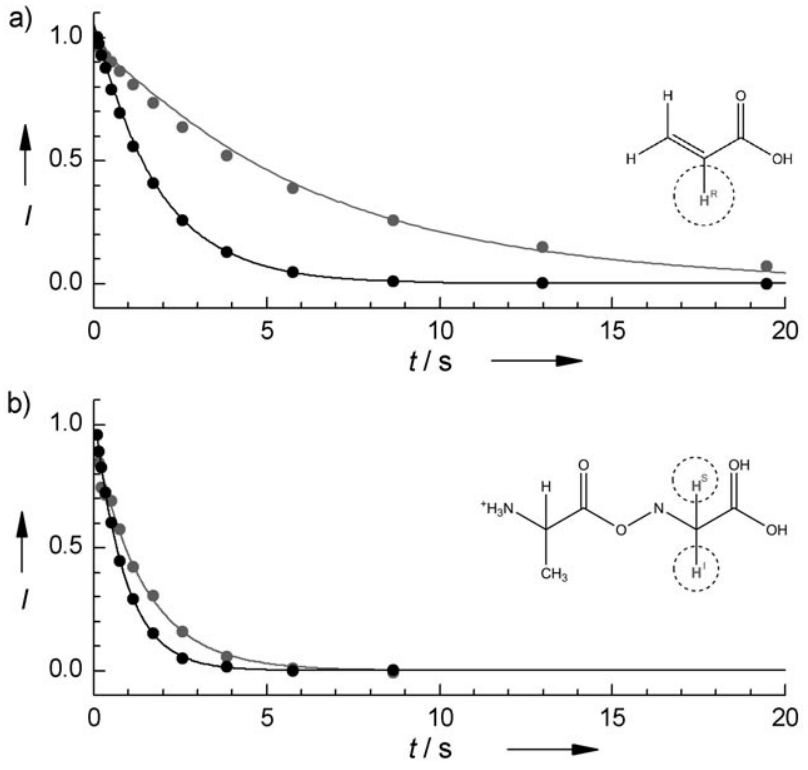

Figure 3. Transverse relaxation times $T_{2}$ (actually $T_{1 \rho}$ determined by spin locking.) a) The proton $\mathrm{H}^{\mathrm{R}}$ in acrylic acid in $\mathrm{D}_{2} \mathrm{O}$ with $2.5 \mathrm{~mm}$ TEMPOL without scavenger $\left(\bullet, T_{2}=1.802 \pm 0.014 \mathrm{~s}\right)$ and after addition of $30 \mathrm{~mm}$ sodium ascorbate $\left(\bullet, T_{2}=6.29 \pm 0.15 \mathrm{~s}\right.$.) b) The two diastereotopic protons $\mathrm{H}^{\prime}$ and $\mathrm{H}^{\mathrm{S}}$ of glycine in L-Ala-Gly in $\mathrm{D}_{2} \mathrm{O}$ with $2.5 \mathrm{~mm}$ TEMPOL without scavenger $\left(\bullet, T_{2}=0.875 \pm 0.008 \mathrm{~s}\right)$ and after addition of $30 \mathrm{~mm}$ sodium ascorbate $\left(\bullet, T_{2}=1.43 \pm 0.095 \mathrm{~s}\right)$.
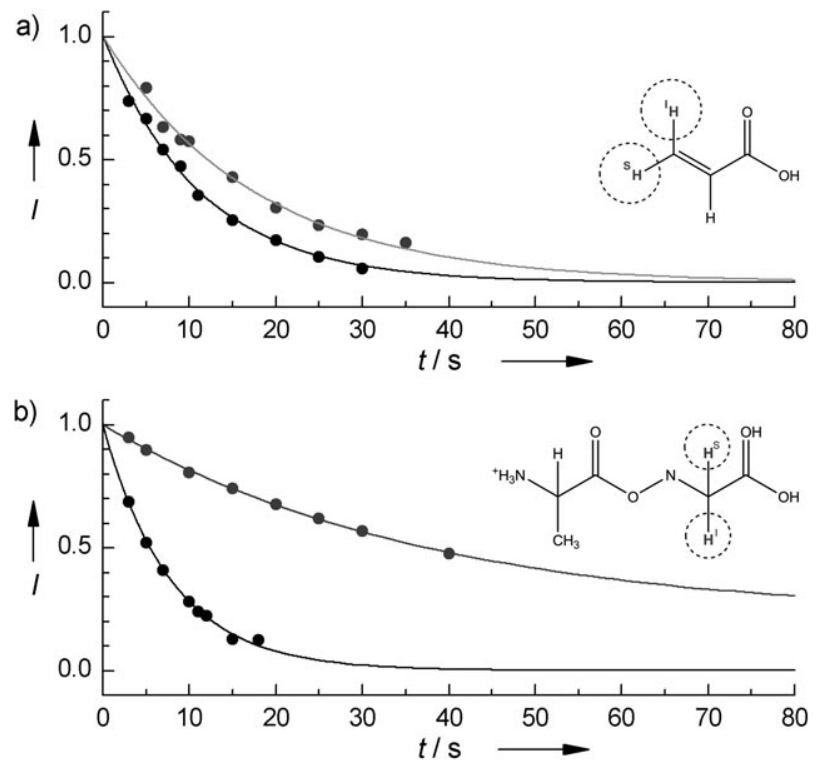

Figure 4. Decay of long-lived states (LLS) involving a) the two protons $\mathrm{H}^{\prime}$ and $\mathrm{H}^{\mathrm{S}}$ in acrylic acid $\left(\mathrm{CH}^{\prime} \mathrm{H}^{\mathrm{S}}=\mathrm{CHCOOH}\right)$, and $\left.\mathrm{b}\right)$ involving the two diastereotopic protons $\mathrm{H}^{\prime}$ and $\mathrm{H}^{\mathrm{S}}$ of glycine in L-Ala-Gly, both at $T=296 \mathrm{~K}$ and $B_{0}=7.05 \mathrm{~T}(300 \mathrm{MHz}$.) In the absence of scavenger $(\bullet)$, the presence of $2.5 \mathrm{~mm}$ TEMPO causes rapid decays

( $T_{\text {LLS }}=11.19 \pm 0.46$ and $7.82 \pm 0.24 \mathrm{~s}$ for acrylic acid and L-Ala-Gly, respectively). The addition of $30 \mathrm{~mm}$ sodium ascorbate (๑) leads to an extension to $T_{\text {LLS }}=17.52 \pm 0.93$ by a of factor 1.6 and $53.7 \pm 1.2 \mathrm{~s}$ by a factor of 7 . 

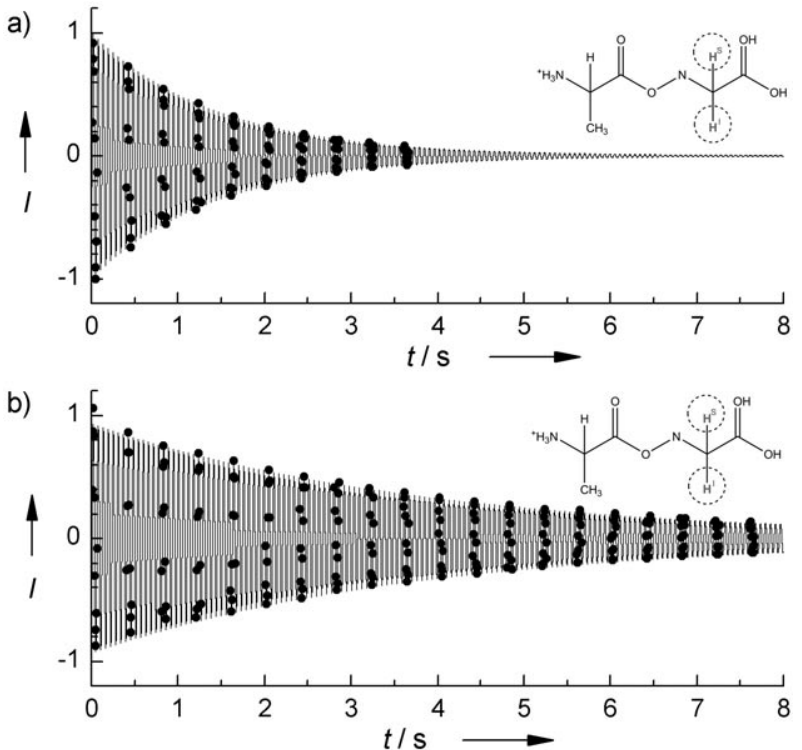

Figure 5. a) The decay of the long-lived coherence (LLC) involving the two protons $\mathrm{H}^{\prime}$ and $\mathrm{H}^{\mathrm{S}}$ of glycine in L-Ala-Gly is affected by the presence of $2.5 \mathrm{~mm}$ TEMPO $\left(T_{\mathrm{LLC}}=1.43 \mathrm{~s}\right)$. b) After addition of $30 \mathrm{~mm}$ sodium ascorbate, the lifetime $\left(T_{\mathrm{LLC}}=3.82 \mathrm{~s}\right)$ is extended by a factor of 2.7. Both signals were measured at $T=296 \mathrm{~K}$ and $B_{0}=7.05 \mathrm{~T}$ without DNP and fitted with mono-exponential decays multiplied by a sine functions. The modulation arises from the scalar coupling constant $J=-17.242 \mathrm{~Hz}$.

sensitivity, thus minimizing the requirement of solute concentrations. Furthermore, when needed, the use of scavengers for in-vivo dissolution DNP experiments will remove toxic free radicals prior to infusion into living animals.

Received: February 15, 2010

Revised: May 5, 2010

Published online: $\mathbf{\square} \mathbf{\square}, 2010$

Keywords: dynamic nuclear polarization - hyperpolarization . NMR spectroscopy $\cdot$ radicals $\cdot$ scavenging

[1] A. Abragam, M. Goldman, Rep. Prog. Phys. 1978, 41, 395-467.

[2] a) A. Comment, B. van den Brandt, K. Uffmann, F. Kurdzesau, S. Jannin, J. A. Konter, P. Hautle, W. T. H. Wenckebach, R. Gruetter, J. J. van der Klink, Concepts Magn. Reson. Part B 2007 , 31, 255-269; b) A. Comment, B. van den Brandt, K. Uffmann, F.
Kurdzesau, S. Jannin, J. A. Konter, P. Hautle, W. T. Wenckebach, R. Gruetter, J. J. van der Klink, Appl. Magn. Reson. 2008, 34, 313 - 319; c) S. Jannin, A. Comment, F. Kurdzesau, J. A. Konter, P. Hautle, B. van den Brandt, J. J. van der Klink, J. Chem. Phys. 2008, 128, 241102.

[3] J. H. Ardenkjaer-Larsen, B. Fridlund, A. Gram, G. Hansson, L. Hansson, M. H. Lerche, R. Servin, M. Thaning, K. Golman, Proc. Natl. Acad. Sci. USA 2003, 100, 10158-10163.

[4] a) M. Carravetta, O. G. Johannessen, M. H. Levitt, Phys. Rev. Lett. 2004, 92, 153003; b) M. Carravetta, M. H. Levitt, J. Chem. Phys. 2005, 122, 214505; c) G. Pileio, M. H. Levitt, J. Chem. Phys. 2009, 130, 214501; d) R. Sarkar, P. R. Vasos, G. Bodenhausen, J. Am. Chem. Soc. 2007, 129, 328-334.

[5] a) G. Pileio, M. Carravetta, M. H. Levitt, Phys. Rev. Lett. 2009, 103, 083002; b) R. Sarkar, P. Ahuja, P. R. Vasos, G. Bodenhausen, Phys. Rev. Lett. 2010, 104, 053001.

[6] B. H. J. Bielski, A. O. Allen, H. A. Schwarz, J. Am. Chem. Soc. 1981, 103, 3516-3518.

[7] F. Kurdzesau, B. van den Brandt, A. Comment, P. Hautle, S. Jannin, J. J. van der Klink, J. A. Konter, J. Phys. D 2008, 41, 155506.

[8] P. R. Vasos, A. Comment, R. Sarkar, P. Ahuja, S. Jannin, J. P. Ansermet, J. A. Konter, P. Hautle, B. van den Brandt, G. Bodenhausen, Proc. Natl. Acad. Sci. USA 2009, 106, 1847518479.

[9] R. Sarkar, A. Comment, P. R. Vasos, S. Jannin, R. Gruetter, G. Bodenhausen, H. Hall, D. Kirik, V. P. Denisov, J. Am. Chem. Soc. 2009, 131, 16014-16015.

[10] a) M. E. Merritt, C. Harrison, Z. Kovacs, P. Kshirsagar, C. R. Malloy, A. D. Sherry, J. Am. Chem. Soc. 2007, 129, $12942-$ 12943; b) A. K. Jindal, M. E. Merritt, E. H. Suh, C. R. Malloy, A. D. Sherry, Z. Kovacs, J. Am. Chem. Soc. 2010, 132, $1784-$ 1785 ; c) P. Miéville, S. Jannin, L. Helm, G. Bodenhausen, J. Am. Chem. Soc. 2010, 132, 5006-5007.

[11] R. B. van Heeswijk, K. Uffmann, A. Comment, F. Kurdzesau, C. Perazzolo, C. Cudalbu, S. Jannin, J. A. Konter, P. Hautle, B. van den Brandt, G. Navon, J. J. van der Klink, R. Gruetter, Magn. Reson. Med. 2009, 61, 1489-1493.

[12] a) D. Bardelang, K. Banaszak, H. Karoui, R. Antal, M. Waite, K. Udachin, J. A. Ripmeester, C. I. Ratcliffe, O. Ouari, P. Tordo, J. Am. Chem. Soc. 2009, 131, 5402-5404; b) A. A. Bobko, I. A. Kirilyuk, I. A. Grigor'ev, J. L. Zweier, V. V. Khramtsov, Free Radical Biol. Med. 2007, 42, 404-412.

[13] J. J. Warren, J. M. Mayer, J. Am. Chem. Soc. 2008, 130, 75467547.

[14] V. A. Roginsky, H. B. Stegmann, Free Radical Biol. Med. 1994, 17, 93-103.

[15] Y. P. Liu, F. A. Villamena, A. Rockenbauer, J. L. Zweier, Chem. Commun. 2010, 46, 628-630.

[16] A. M. Leach, P. Miller, E. Telfeyan, D. B. Whitt (General Electric), USA US2009263325A1, 2009. 


\section{Communications}

NMR Spectroscopy

P. Miéville, P. Ahuja, R. Sarkar, S. Jannin,*

P. R. Vasos, S. Gerber-Lemaire,

M. Mishkovsky, A. Comment, R. Gruetter,

O. Ouari, P. Tordo,

G. Bodenhausen

IIII-IIII

Scavenging Free Radicals To Preserve

Enhancement and Extend Relaxation

Times in NMR using Dynamic Nuclear

Polarization
Vitamin $\mathrm{C}$ for longer lifetimes: $\mathrm{N}$-oxide radicals that are widely used for dynamic nuclear polarization can be reduced by scavengers such as sodium ascorbate (vitamin C) during the dissolution process, thus diminishing losses of polarization during the transfer and extending transverse and longitudinal relaxation times in NMR spectroscopy (see picture). 